\title{
Influence of viscosity variation on ferrofluid based long bearing
}

\author{
Jimit R. Patel ${ }^{1}$, G. M. Deheri ${ }^{2}$ \\ ${ }^{1}$ Department of Mathematical Sciences, P. D. Patel Institute of Applied Sciences, Charotar University of Science and \\ Technology (Charusat), Gujarat, India, e-mail: patel.jimitphdmarch2013@gmail.com \\ ${ }_{2}^{2}$ Department of Mathematics, Sardar Patel University, Vallabh Vidyanagar, Anand, Gujarat, India, e-mail: \\ gm.deheri@rediffmail.com
}

\begin{tabular}{|c|c|}
\hline Article Info & ABSTRACT \\
\hline $\begin{array}{l}\text { Article history: } \\
\text { Received October 19, } 2021 \\
\text { Revised December 20, } 2020 \\
\text { Accepted December 24, } 2020\end{array}$ & \multirow[t]{3}{*}{$\begin{array}{l}\text { This paper deals with a theoretical analysis on the effect of viscosity variation } \\
\text { on a ferrofluid based long bearing. The model of Tipei considering viscosity } \\
\text { variation is deployed here. The magnetic fluid flow is governed by Neuringer- } \\
\text { Rosensweig model. The pressure distribution is obtained after solving the } \\
\text { associated Reynolds type equation, which gives the load carrying capacity. } \\
\text { The computed results indicate that the increased load carrying capacity owing } \\
\text { to magnetization gets negligible help from the effect of viscosity variation. }\end{array}$} \\
\hline \multirow[t]{2}{*}{ 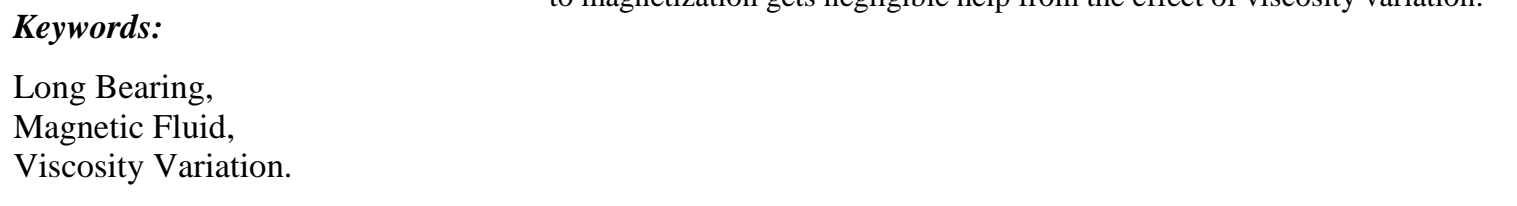 } & \\
\hline & \\
\hline & $\begin{array}{r}\text { Copyright (C)2022 Regional Association for Security and crisis management } \\
\text { and European centre for operational research. } \\
\text { All rights reserved. }\end{array}$ \\
\hline \multicolumn{2}{|l|}{ Corresponding Author: } \\
\hline \multicolumn{2}{|c|}{$\begin{array}{l}\text { Jimit R. Patel, } \\
\text { Department of Mathematical Sciences, P. D. Patel Institute of Applied Sciences, Charotar University of Science and } \\
\text { Technology (Charusat), Changa, Gujarat, India. } \\
\text { Email: patel.jimitphdmarch2013@gmail.com }\end{array}$} \\
\hline
\end{tabular}

\section{Introduction}

A magnetic fluid is a liquid that is strongly magnetized when an applied magnetic field is present. It is a colloid made of nanoscale mono-domain ferromagnetic particles suspended in a carrier fluid (water, oil or other organic solvent). These particles float due to the Brownian motion and do not settle or aggregate under normal conditions. Magnetic fluids are drawn by dielectric (nonconductive) and paramagnetic (magnetic fields) and do not maintain magnetization in the absence of applied magnetic fields.

The magnetic fluid can be controlled using an external magnetic field, enabling a rich control-based application. Recent interest in ferrofluids is related to technical applications such as instrumentation, vacuum technology, lubrication, vibration damping, radar absorbing materials and sound. For example, liquid sealant on hard disk drive shafts, vibration control and braking of vehicles, and improved heat transfer of electronic devices are same. Other potential applications include micro/nano electromechanical systems: selfmanipulation of micro-channel flow, particle separation, nano-motors, microelectronic generators and nano pumps. By the application of a suitable magnetic field, the viscosity of the ferrofluid increases leading to the enhanced load carrying capacity (Odenbach, 2003), Chandra et al., 1992). A number of authors dealt with the effect of magnetic fluid in different types of bearing for instance; Tipei (1982) in short bearing, Agrawal (1986), Shah and Bhat (2003) and Deheri and Patel (2011) in slider bearing, journal bearing by Nada and Osman (2007) and Patel el al. (2012), circular plates by Shah and Bhat (2000), Deheri and Abhangi (2011), Patel and Deheri (2014, 2015), Patel and Deheri (2016) in Annular plates and Parrallel slider bearing by Patel and Deheri (2016) . Most of all concluded that bearing performance might be increase due to magnetic fluid lubrication. 
The traditional hypothesis of long bearing is a well-established in literature [(Majumdar, 2008), (Hemrock 1994), (Szeri, 1998)]. In literature, most of the studies [(Urreta et al., 2009), (Deheri et al., 2010), (Deresses and Sinha, 2011), (Patel and Deheri, 2016) and (Patel at al., 2016) considered that viscosity is constant, but it is unrealistic approach due to some running conditions of bearing. Patel and Deheri (2019) examined the performance of a magnetic fluid based short bearing considering the viscosity variation. It was established that the positive effect of viscosity variation gets aided considerably by the ferrofluid lubrication. Patel and Patel (2020) discussed the impact of the rotation of Ferro-particles and slip velocity at the boundary of Shliomis model based squeeze porous curved annular plates. It was noticed that the bearing's performance enhanced due to ferrofluid, considering the appropriate values of parameters for slip velocity and porosity.

Most of the accessible studies deal with either pressure and load carrying capacity or friction and wear. In addition, only few papers have focused on viscosity variation aspects of lubrication for various bearings, solely, from tribological performance point of view. Therefore, it was deliberation suitable to present a study of a theoretical analysis on the effect of viscosity variation on a ferrofluid based long bearing.

\section{Analysis}

The geometry of the infinitely long bearing displays in Figure 1 . The bearing system is infinite in $Z$ direction. The slider travels with uniform velocity $u$ in $X$ direction. In bearing system, $L$ is the length of the bearing and the breadth $B$ is in $Z$ direction.

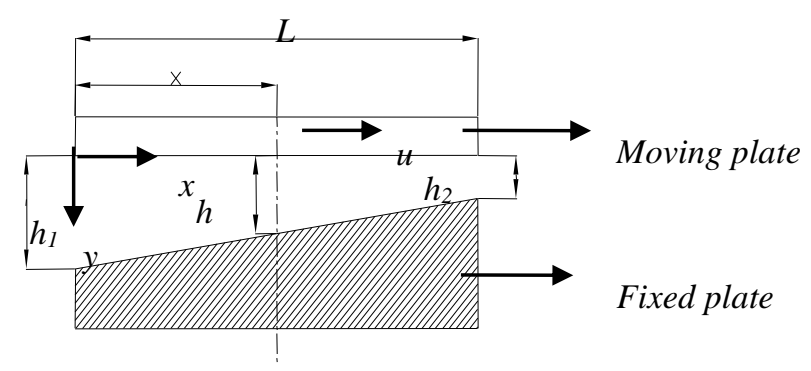

Figure 1. Geometry of the bearing system

In this study, it is considered that the lubricant film is isoviscous, incompressible and the flow is laminar.

As per the theory of Agrawal (1986), here assume the ferrofluid lubrication effect by taking the magnetic field oblique to the stator. Prajapati (1995) produced the effect of various forms of magnitude of the magnetic field. Following this discussion here, the magnitude of the magnetic field is taken to be

$$
\mathrm{M}^{2}=\mathrm{kL}^{2}(\mathrm{x} / \mathrm{L}) \sin \left(1-\frac{\mathrm{x}}{\mathrm{L}}\right)
$$

Here $\mathrm{k}$ is a suitably chosen constant from dimensionless point of view so as to produce a magnetic field of strength over $10^{-23}$ (Bhat and Deheri (1995)).

Neuringer and Rosensweig (1964) produced a model for the consistent flow of magnetic fluids within the presence of gradually changing external magnetic fields. This contained the succeeding equations:

$$
\begin{gathered}
\rho(\overline{\mathrm{q}} \nabla) \overline{\mathrm{q}}=-\nabla \mathrm{p}+\eta \nabla^{2} \overline{\mathrm{q}}+\mu_{0}(\overline{\mathrm{M}} \nabla) \overline{\mathrm{H}} \\
\nabla \overline{\mathrm{q}}=0 \\
\nabla \times \overline{\mathrm{H}}=0 \\
\overline{\bar{M}}=\bar{\mu} \overline{\mathrm{H}} \\
\nabla(\overline{\mathrm{H}}+\overline{\mathrm{M}})=0
\end{gathered}
$$

where $\rho$ is the fluid density, $\overline{\mathrm{q}}$ stand for the fluid velocity in the film region, $\overline{\mathrm{H}}$ being external magnetic field, $\bar{\mu}$ denotes magnetic susceptibility of the magnetic field, pindicates the film pressure, $\eta$ signifies the fluid viscosity and $\mu_{0}$ denotes the permeability of the free space. The points of concern about this aspects can be establish in Bhat (2003), Prajapati (1995) and Patel and Deheri (2016).

Using equations (3)-(6), equation (2) becomes

$$
\rho(\overline{\mathrm{q}} \nabla) \overline{\mathrm{q}}=-\nabla\left(\mathrm{p}-\frac{\mu_{0} \bar{\mu}}{2} \mathrm{M}^{2}\right)+\eta \nabla^{2} \overline{\mathrm{q}}
$$

This indicates that an extra term in pressure $\frac{\mu_{0} \bar{\mu}}{2} \mathrm{M}^{2}$ is modification into the Navier-Stokes equation when a magnetic fluid is considered as a lubricant. 
Under the common assumptions of hydro magnetic lubrication (Bhat (2003), Prajapati (1995), Deheri et al. (2005)) the modified Reynolds equation governing the pressure distribution is derived as

$$
\frac{\mathrm{d}}{\mathrm{dx}}\left[\mathrm{p}-\frac{\mu_{0} \bar{\mu} \mathrm{M}^{2}}{2}\right]=6 \mu \mathrm{u}\left(\frac{\mathrm{h}-\lambda \mathrm{h}_{2}}{\mathrm{~h}^{3}}\right)
$$

while $\mu_{0}$ being the magnetic susceptibility, $\bar{\mu}$ denotes the free space permeability, $\mu$ is the lubricant viscosity and $\lambda$ stands for a constant to be determined.

It has been confirmed experimentally that the most elevated temperature happened in zones where the film thickness was least (Tipei (1962)). Here one can think about the thermal impact considering the viscositytemperature connection as when the viscosity $\mu_{1}$ at $h=h_{1}$ (lubricant inlet condition) is known, at that point

$$
\mu=\mu_{1}\left\{\frac{\mathrm{h}}{\mathrm{h}_{1}}\right\}^{\mathrm{q}}
$$

where q normally lies between 0 and 1 (according to the nature of the lubrication).

The boundary conditions are

$$
\mathrm{p}=0 \text { at } \mathrm{x}=0 \text { and } \mathrm{x}=\mathrm{L}
$$

The following non dimension quantities are introduced

$$
\begin{gathered}
\mathrm{m}=\frac{\mathrm{h}_{1}-\mathrm{h}_{2}}{\mathrm{~h}_{2}}, \mathrm{~h}=\mathrm{h}_{2}\left\{1+\mathrm{m}\left(1-\frac{\mathrm{x}}{\mathrm{L}}\right)\right\}, \mathrm{P}=\frac{\mathrm{h}_{2}^{3}}{\mu_{1} \mathrm{uL}} \mathrm{p}, \mu^{*}=\frac{\mathrm{h}_{2}^{3} \mathrm{k} \mu_{0} \bar{\mu}}{\mu_{1} \mathrm{u}}, \mathrm{X}=\frac{\mathrm{x}}{\mathrm{L}}, \overline{\mathrm{h}}_{2}=\frac{\mathrm{h}_{2}}{\mathrm{~L}}, \\
\overline{\mathrm{h}}_{1}=\frac{\mathrm{h}_{1}}{\mathrm{~h}_{2}}, \mathrm{~A}=1+\mathrm{m}(1-\mathrm{X})
\end{gathered}
$$

Using equation (8) and (9) in equation (7), the dimensionless pressure is obtained in the form of,

where

$$
P=\frac{\mu^{*}}{2} X(1-X)+\frac{\left(\bar{h}_{2}\right)^{q+1}}{\left(\bar{h}_{1}\right)^{q}}\left[\frac{A^{q-1}}{(-m)(q-1)}-\lambda \frac{A^{q-2}}{(-m)(q-2)}+C_{1}\right]
$$

$$
\lambda=\left(\frac{\mathrm{q}-2}{\mathrm{q}-1}\right) \frac{1-(1+\mathrm{m})^{\mathrm{q}-1}}{1-(1+\mathrm{m})^{\mathrm{q}-2}}, \mathrm{C}_{1}=\frac{1}{\mathrm{q}-1}\left[\frac{(1+\mathrm{m})^{\mathrm{q}-2}}{1-(1+\mathrm{m})^{\mathrm{q}-2}}\right]
$$

The non-dimensional load carrying capacity then, is derived as

where

$$
W=\frac{\mu^{*}}{12}+\frac{\left(\bar{h}_{2}\right)^{q+1}}{\left(\bar{h}_{1}\right)^{q}}\left[\frac{1-(1+m)^{q-1}}{m^{2} q(q-1)}-\lambda \frac{\left\{1-(1+m)^{q-1}\right\}}{m^{2}(q-1)(q-2)}+C_{1}\right]
$$

$$
\mathrm{W}=\frac{\overline{\mathrm{h}}_{2}^{3}}{\mu_{1} \mathrm{uL}^{4}} \mathrm{~W}=\int_{0}^{1} \mathrm{PdX}
$$

\section{Results and Discussion}

Equation (11) determines the non-dimensional load carrying capacity of the Long bearing. It is manifest that the load carrying capacity enhances by $\frac{\mu^{*}}{12}$ as compared to the case of usual lubricant based bearing system. This is possibly due to the fact that the viscosity of the lubricant gets augmented owing to magnetization, there by leading to increased pressure and hence the load carrying capacity. A close glance at the expression of the load indicates that the expression is linear with respect to the magnetization parameter. This means an enhancement in the magnetization parameter would always result in better load carrying capacity. This can be seen from the following graphical representations (Figure 2-5).

The effect of $m, q$ and $h_{1} / \mathrm{L}(=h 1 / L)$ on load carrying capacity with respect to $\mu^{*}$ remains negligible (Figure 2-5). On the other hand the effect of $h_{1} / \mathrm{L}$ is quite significant. 


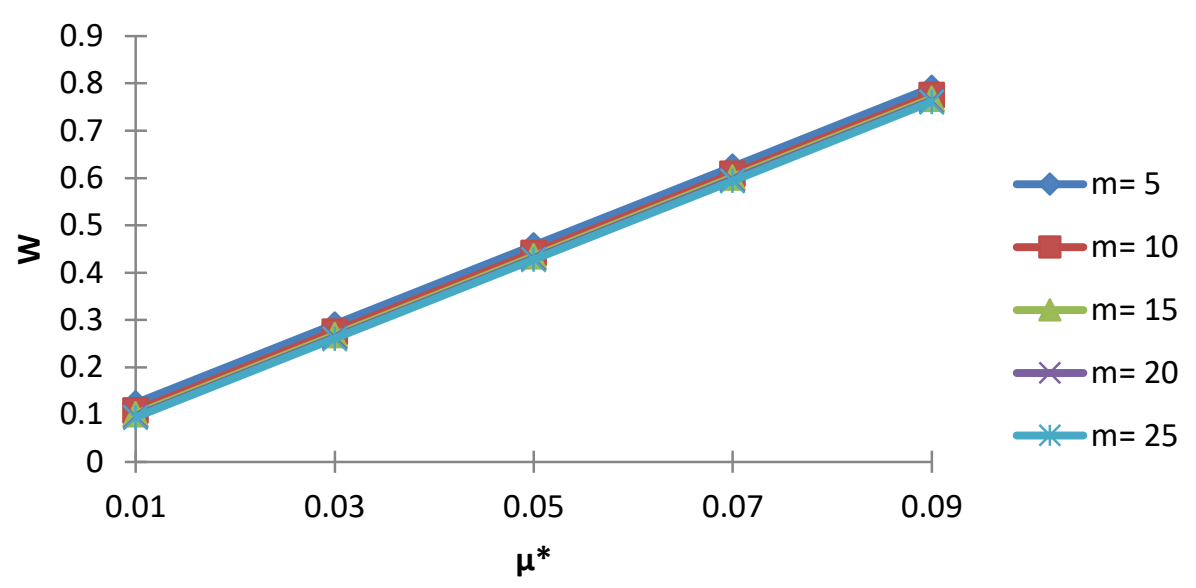

Figure 2. Variation of $W$ with respect to $\mu^{*}$ and $m$.

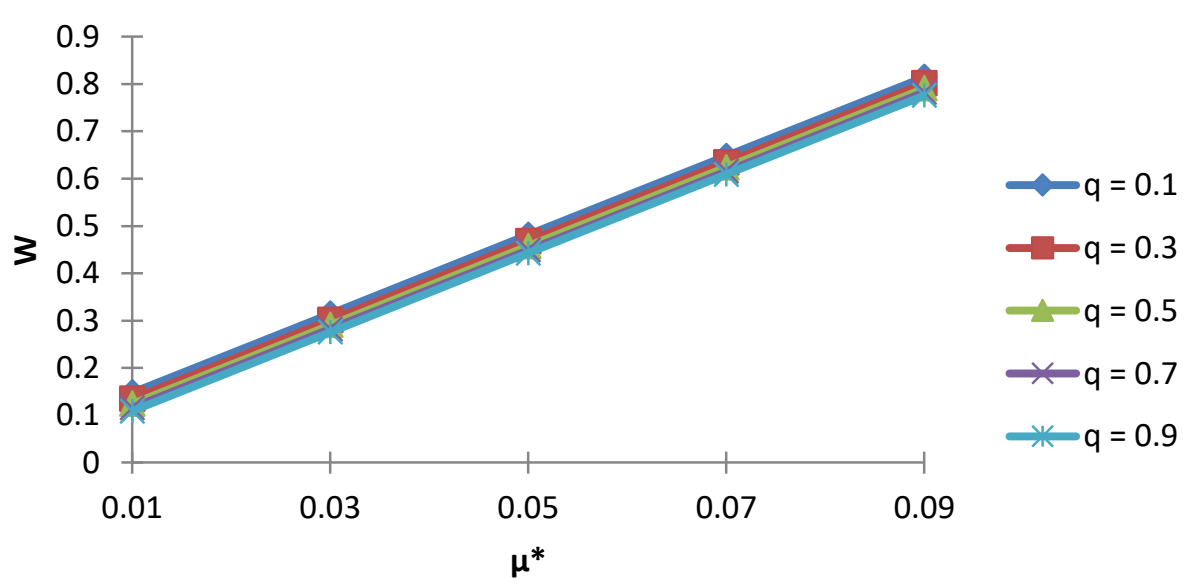

Figure 3. Variation of $W$ with respect to $\mu^{*}$ and $q$.

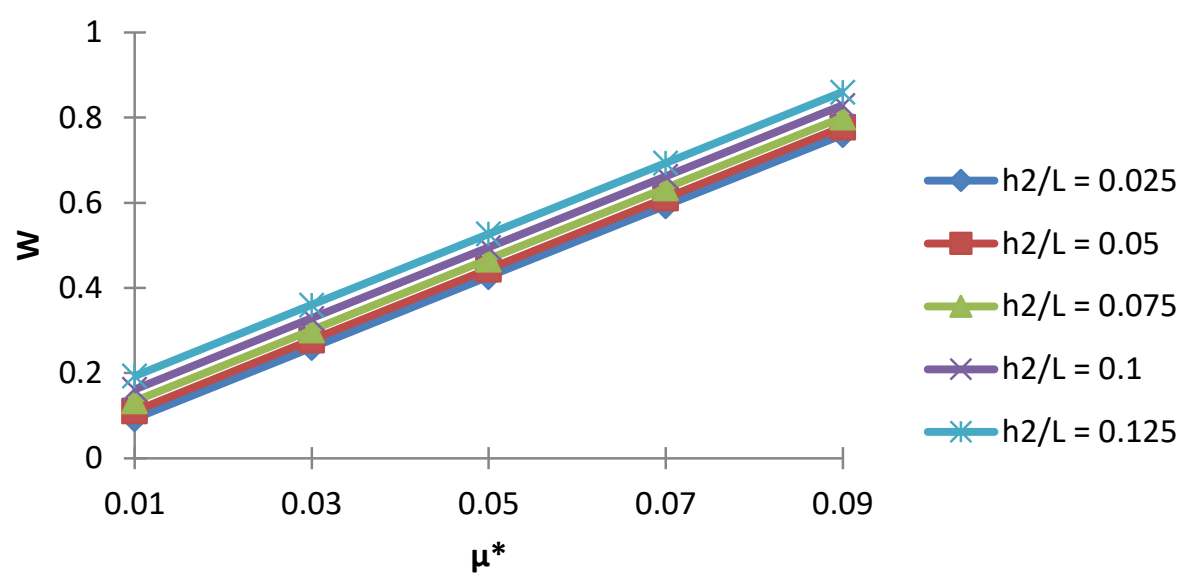

Figure 4. Variation of $W$ with respect to $\mu^{*}$ and $h 2 / L$. 


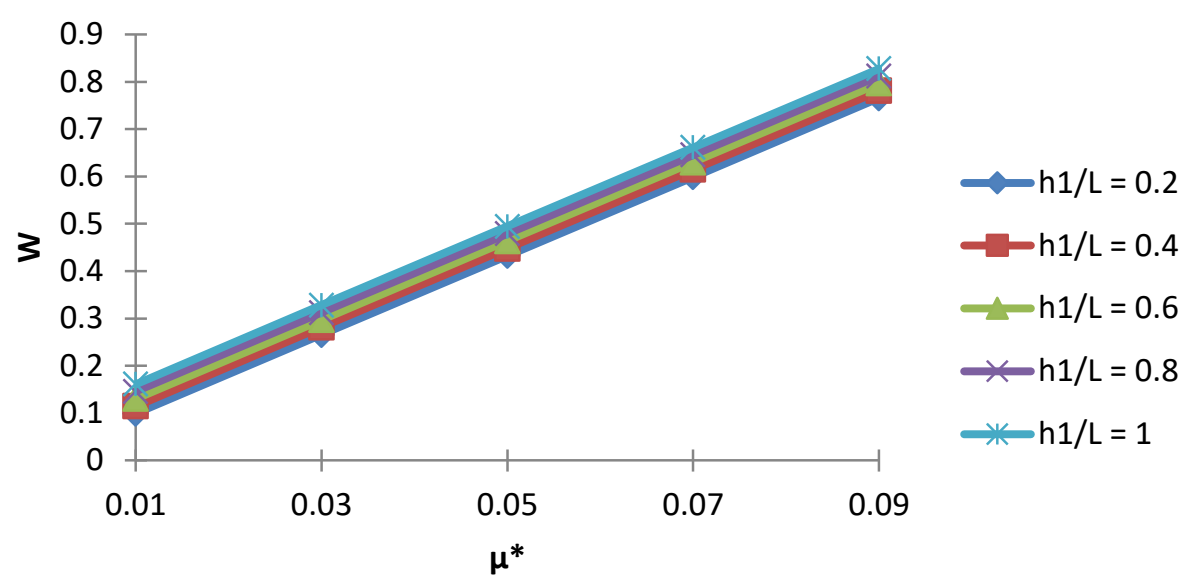

Figure 5. Variation of $W$ with respect to $\mu^{*}$ and $h 1 / L$.

The opposite nature of $h_{1} / \mathrm{L}$ and $h_{2} / \mathrm{L}(=h 2 / L)$ on the distribution of load with respect to $m$ is observed in Figure 6-8.

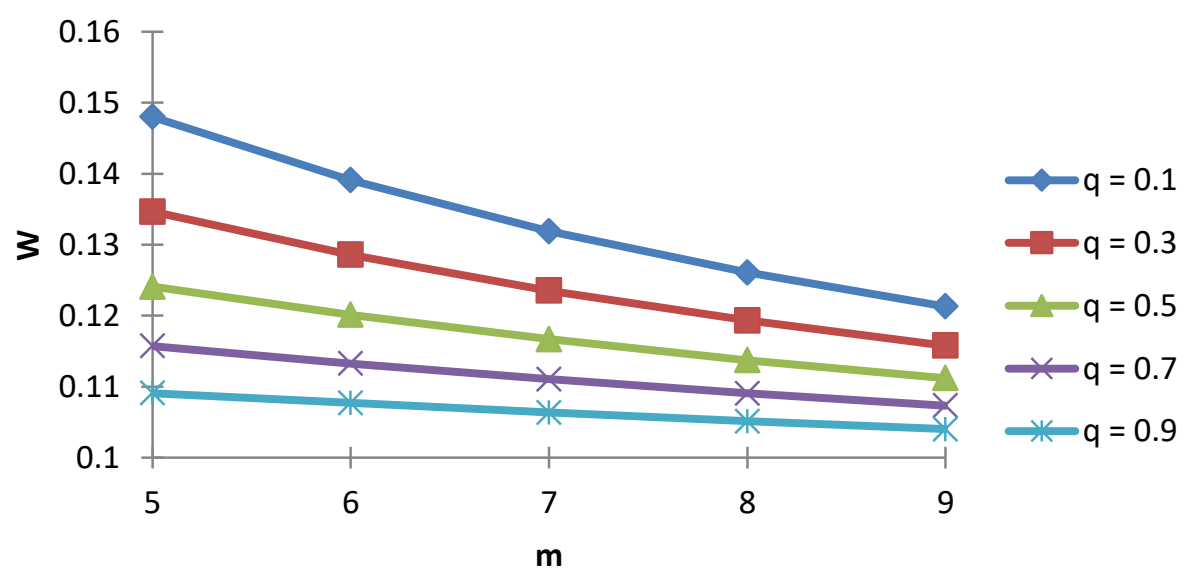

Figure 6. Variation of $W$ with respect to $m$ and $q$.

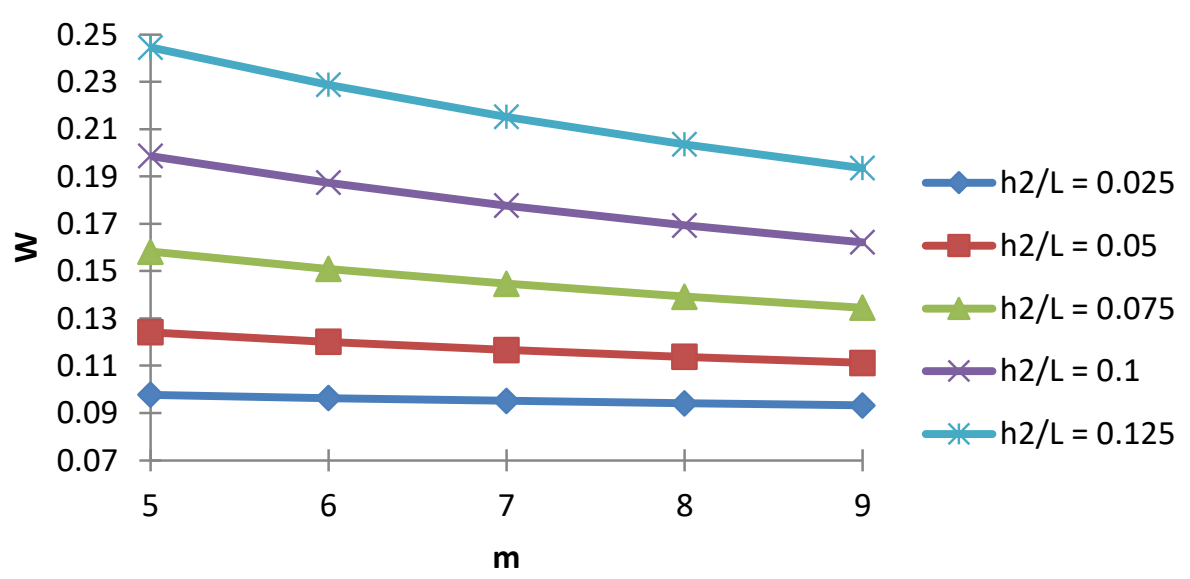

Figure 7. Variation of $W$ with respect to $m$ and $h 2 / L$. 


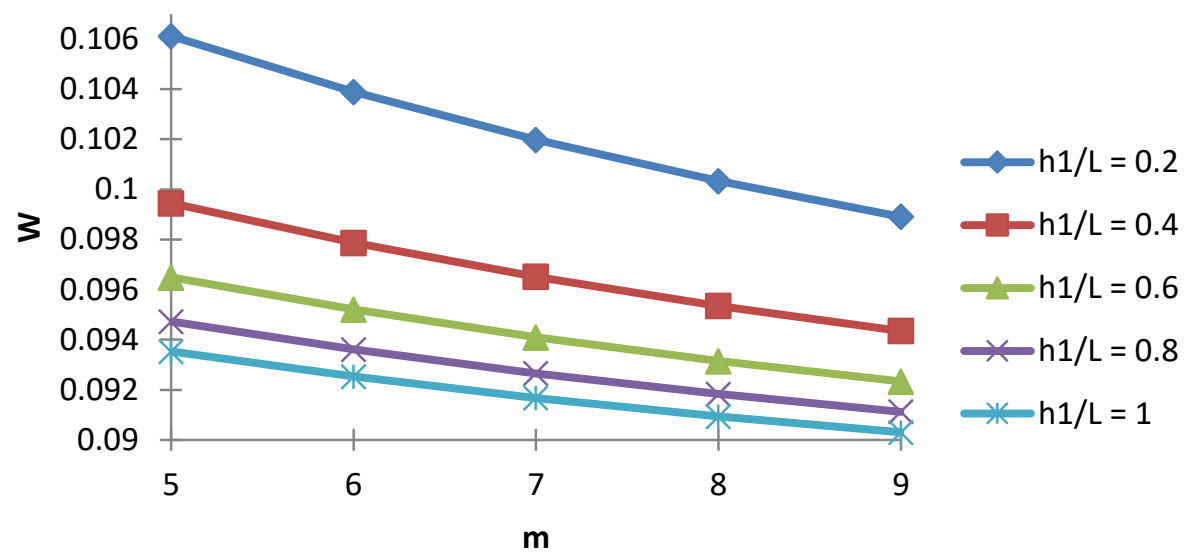

Figure 8. Variation of $W$ with respect to $m$ and $h 1 / L$.

In Figure 9 and 10, Again the trends of load carrying capacity with respect to $q$ remains oppositr for $h_{1} / \mathrm{L}$ and $h_{2} / \mathrm{L}$, the decrease in load carrying capacity being more at the initial stag for $h_{1} / \mathrm{L}$.

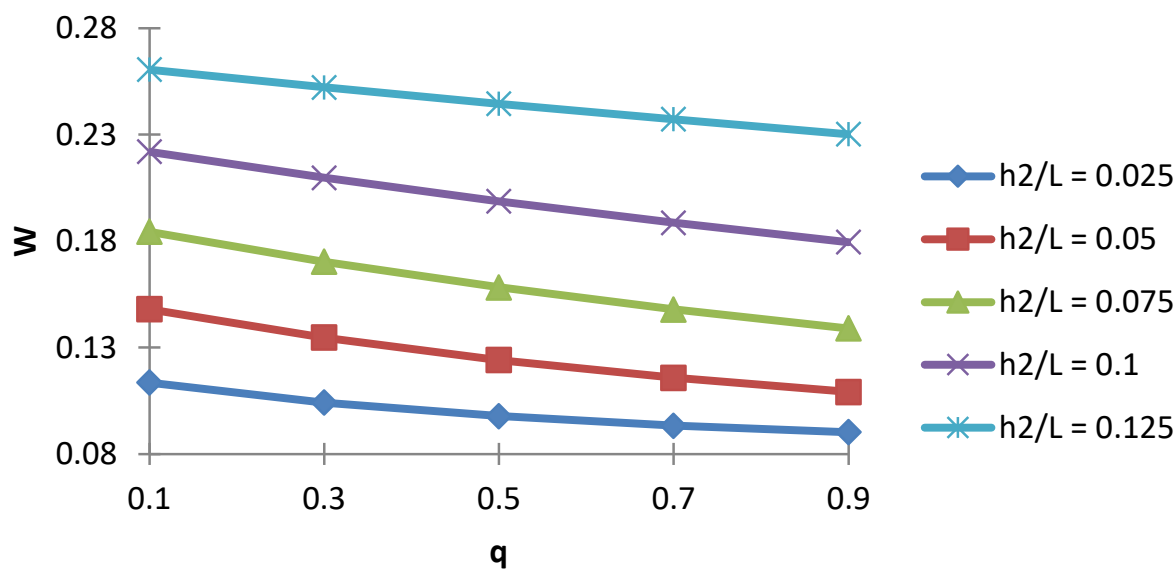

Figure 9. Variation of $W$ with respect to $q$ and $h 2 / L$.

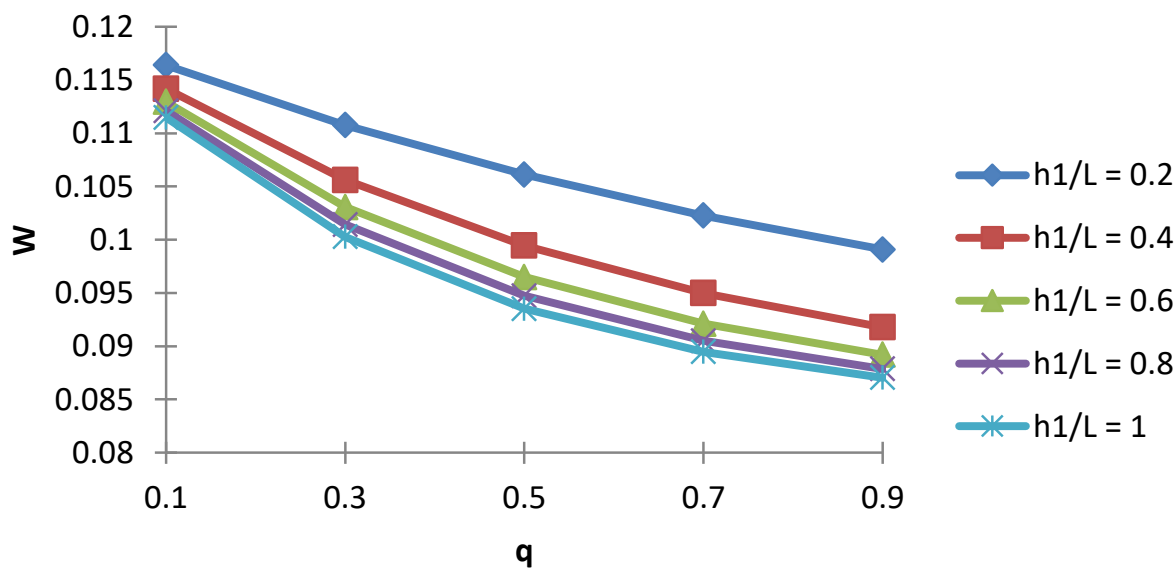

Figure 10. Variation of $W$ with respect to $q$ and $h 1 / L$.

Figure 11 says that role of ratios $h_{2} / L$ and $h_{2} / L$ remain crucial for bearing design. 


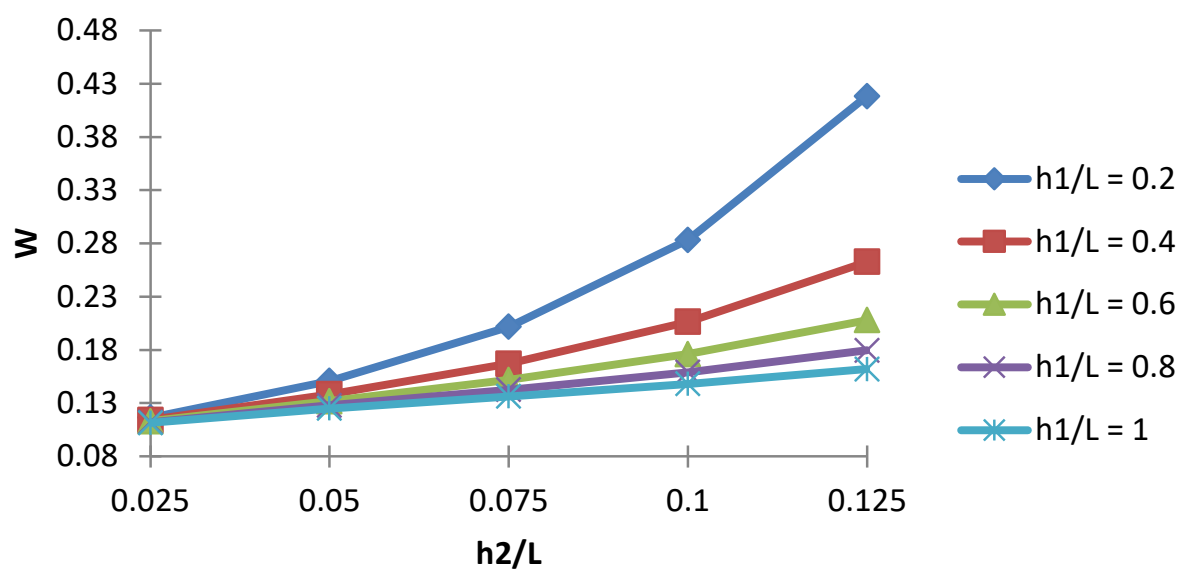

Figure 11. Variation of $W$ with respect to $h 2 / L$ and $h 1 / L$.

Equation (11) also makes it clear that this type of bearing system sustains some amount of load even in the absence of the flow, which is very much unlikely in the case of a conventional lubricant based bearing system. The load can be further raised, by choosing a suitably range of viscosity variation.

The graphical pictures offer the suggestions that, the viscosity variation effect remains at the most nominal so far as the load bearing capacity with respect to magnetization is concerned. Also, the viscosity variation turns in a little aid to $\mu^{*}$ in augmenting the load capacity.

\section{Conclusion}

Studies have been made to deal with the effect of viscosity variation on the performance of a conventional lubricant based bearing system. But, literature facts to give the effect of viscosity variation on long bearing with a magnetic fluid lubricant. So, it was thought appropriate launch an investigation into the performance of a magnetic fluid based long bearing considering viscosity variation.

This investigation offers the suggestion that the magnetic fluid plays a vital role in augmenting the bearing performance. Undoubtedly, the effect of viscosity variation fails to deliver positively for this type of bearing system always. It at all this type of bearing system is to be used then suitable magnetic strength must be given due priority. However, it is strongly felt that if designed properly, this type of bearing system may be put in use by the industry.

This investigation beacons the researchers to extend this analysis in the following directions:

1) Extending the analysis of this work to incorporating the roughness effect on the bearing system, as always bearing surfaces are rough to some extent (may be negligible).

2) This analysis can be conducted by considering the other two magnetic fluid flow models namely: Jenkins and Shliomis.

Acknowledgement: The authors acknowledge with due respect the comments and suggestions of Editors.

\section{References}

Agrawal, V.K. (1986). Magnetic-fluid-based porous inclined slider bearing. Wear, 107(2), 133-139.

Bhat, M.V. \& Deheri, G.M. (1995). Porous slider bearing with squeeze film formed by a magnetic fluid. Pure and Applied Mathematika Sciences, 39(1-2), 39-43.

Bhat, M.V. (2003). Lubrication with a Magnetic fluid. India: Team Spirit (India) Pvt. Ltd.

Chanda, P., Sinha, P. \& Kumar, D. (1992). Ferrofluid lubrication of a journal bearing considering cavitation. Tribology Transactions, 35(1), 163-169. 
Deheri, G.M. \& Abhangi, N.D. (2011). Numerical modelling of a magnetic fluid-based squeeze film between rotating transversely rough curved circular plates. International Journal of Computational Materials Science and Surface Engineering, 4(3), 185-204.

Deheri, G.M. \& Patel, J.R. (2011). Magnetic Fluid Based Squeeze Film in a Rough Porous Parallel Plate Slider Bearing. Annals of Faculty Engineering Hunedoara - International Journal of Engineering, IX (3), 443-448.

Deheri, G.M., Andharia, P.I. \& Patel, R.M. (2005). Transversely rough slider bearings with squeeze film formed by a magnetic fluid. Int. J. of Applied Mechanics and Engineering, 10(1), 53-76.

Deheri, G.M., Changela, C.D., Patel, H.C. \& Abhangi, N.D. (2010). Performance of an infinitely long transversely rough hydrodynamic slider bearing. Advanced Tribology: Proceedings of CIST2008 \& ITSIFToMM2008, 262-263.

Deresse, G.A. \& Sinha, P. (2011). THD analysis for finite slider bearing with roughness: special reference to load generation in parallel sliders. Acta Mech., 222, 1-15.

Hamrock, B.J. (1994). Fundamentals of Fluid film Lubrication. New York: McGraw-Hill Inc.

Majumdar, B.C. (2008). Introduction to Tribology of Bearings. New Delhi: S. Chand and Company Limited, India.

Nada, G.S. \& Osman, T.A. (2007). Static performance of finite hydrodynamic journal bearings lubricated by magnetic fluids with couple stresses. Tribology Letters, 27(3), 261- 268.

Neuringer, J.L. \& Rosensweig, R.E. (1964). Magnetic Fluids, Magnetic Fluid. Physics of Fluids, 7(12), 1927.

Odenbach (2003). Ferrofluids-magnetically controlled suspensions. Colloids Surfaces A: Physicochem. Eng. Asp, 217, 171-178.

Patel, J.R, Deheri, G.M. \& Patel, Sejal J. (2017). Ferrofluid Lubrication of a Rough Porous Secant-Shaped Slider Bearing with Slip Velocity. Journal of the Serbian Society for Computational Mechanics, 11(1), 69-81.

Patel, J.R. \& Deheri, G.M. (2014). Effect of various porous structures on the Shliomis model based ferrofluid lubrication of the film squeezed between rotating rough curved circular plates, Facta Universitatis, series: Mechanical Engineering, 12(3), 305-323.

Patel, J.R. \& Deheri, G.M. (2015). Jenkins Model Based Magnetic Squeeze Film In Curved Rough Circular Plates Considering Slip Velocity: A Comparison Of Shapes. FME Transactions, 43(2), 144-153.

Patel, J.R. \& Deheri, G.M. (2016). A study of thin film lubrication at nanoscale for a ferrofluid based infinitely long rough porous slider bearing. Facta Universitatis Series: Mechanical Engineering, 14(1), 89 - 99.

Patel, J.R. \& Deheri, G.M. (2016). Combined Effect of Slip Velocity and Roughness on the Jenkins Model Based Ferrofluid Lubrication of a Curved Rough Annular Squeeze Film. Journal of Applied Fluid Mechanics, 9(2), 855-865.

Patel, J.R. \& Deheri, G.M. (2016). Performance of a Ferrofluid Based Rough Parallel Plate Slider Bearing: A Comparison of Three Magnetic Fluid Flow Models. Advances in Tribology, 2016, Article ID 8197160, 1-9.

Patel, J.R. \& Deheri, G.M. (2019). Viscosity variation effect on the magnetic fluid lubrication of a short bearing. Journal of the Serbian Society for Computational Mechanics, 13(2), 56-66.

Patel, N.C. \& Patel, J.R. (2020). Magnetic fluid-based squeeze film between curved porous annular plates considering the rotation of magnetic particles and slip velocity. Journal of the Serbian Society for Computational Mechanics. 14(2), 69-82.

Patel, N.S., Vakharia, D.P. \& Deheri, G.M. (2012). A study on the performance of a magnetic-fluid-based hydrodynamic short journal bearing. ISRN Mechanical Engineering, 2012, Article ID 603460.

Prajapati, B.L. (1995). On Certain Theoretical Studies in Hydrodynamic and Electro-magneto hydrodynamic Lubrication. Ph. D. Thesis: S.P. University. Vallabh Vidyanagar, Anand, India.

Shah, R.C. \& Bhat, M.V. (2000). Squeeze film based on magnetic fluid in curved porous rotating circular plates. Journal of Magnetism and Magnetic Materials, 208(1), 115-119. 
Shah, R.C. \& Bhat, M.V. (2003). Magnetic fluid based porous inclined slider bearing with velocity slip. Int. J. of Applied Mechanics and Engineering, 18(2), 331-336.

Szeri, A.Z. (1998). Fluid Film Lubrication: Theory and Design. New York: Cambridge Univ. Press.

Tipei, N. (1982). Theory of lubrication with ferrofluids: application to short bearings. Transactions of ASME, 104, 510-515.

Urreta, H., Leicht, Z., Sanchez, A., Agirre, A., Kuzhir, P. \& Magnac, G. (2009). Hydrodynamic bearing lubricated with magnetic fluids. Journal of Physics: Conference series. 149(1), Article ID 012113. 